Universidad

:

BIBLIOTECA

Document downloaded from the institutional repository of the University of Alcala: https://ebuah.uah.es/dspace/

This is a postprint version of the following published document:

Sessini, V. et al., 2018. Humidity-activated shape memory effect on plasticized starch-based biomaterials. Carbohydrate Polymers, 179, pp.9399.,

Available at https://doi.org/10.1016/i.carbpol.2017.09.070

(C) 2017 Elsevier

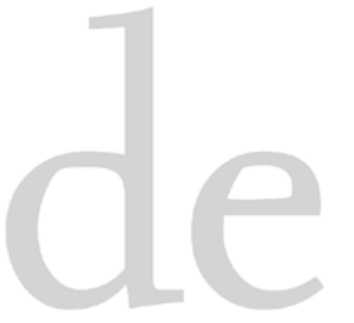

(Article begins on next page)

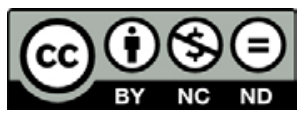

This work is licensed under a

Creative Commons Attribution-NonCommercial-NoDerivatives

4.0 International License. 
(C) <2017>. This manuscript version is made available under the CC-BY-NC-ND 4.0 license http://creativecommons.org/licenses/by-nc-nd/4.0/

\section{Humidity-activated shape memory effect on plasticized}

\section{2 starch-based biomaterials.}

3 Valentina Sessini ${ }^{\mathrm{a}, \mathrm{b}}$, Marina P. Arrieta ${ }^{\mathrm{b}}$, Alberto Fernández-Torres ${ }^{\mathrm{b}}$ and Laura Peponi $\mathrm{b}^{*}$

$4{ }^{a}$ Dipartimento di Ingegneria Civile e Ambientale, Università di Perugia, Strada di Pentima,

505100 Terni, Italy

$6{ }^{b}$ Instituto de Ciencia y Tecnología de Polímeros, ICTP-CSIC, calle Juan de la Cierva 3, 28006,

7 Madrid, Spain.

8 ABSTRACT

9 Humidity-activated shape memory behaviour of plasticized starch-based films

10 reinforced with the innovative combination of starch nanocrystals (SNCs) and catechin

11 as antioxidant were studied. In a previous work, we reported the processing of

12 gelatinized starch-based films filled with SNCs and catechin as antioxidant agent, and

13 we observed that this novel combination leads to starch-based film with enhanced

14 thermal and mechanical performance. In this work, the humidity-activated shape

15 memory behavior of the previous developed starch-based films was characterized. The

16 moisture loss as well as the moisture absorption were studied since they are essential

17 parameters in humidity-activated shape memory polymers to fix the temporary shape

18 and to recover the original shape, respectively. Therefore, the effect of the incorporation

19 of SNCs and catechin on the humidity-activated shape memory properties of plasticized

20 starch was also studied. Moreover, the effectiveness of catechin to increase the polymer

21 stability under oxidative atmosphere and the thermo-mechanical relaxation of all the

22 starch-based materials were studied. The combination of plasticized starch matrix

23 loaded with both, SNCs and catechin, leads to a multifunctional starch-based films with

24 increased hydrophilicity and with excellent humidity-activated shape memory behavior

25 with interest for potential biomedical applications. 
(C) <2017>. This manuscript version is made available under the CC-BY-NC-ND 4.0 license http://creativecommons.org/licenses/by-nc-nd/4.0/

Highlights

- The humidity-activated shape memory behaviour of starch biomaterials was studied;

- The shape memory mechanism was based on the plasticizing effect of humidity;

- The presence of SNCs and Cat, produced a significant increase on the $\mathrm{R}_{\mathrm{r}}$ values.

Keywords: starch, shape memory, bending, catechin, humidity.

\section{Introduction}

Shape memory polymers (SMPs) have gained considerable interest during the last years in both academics and industrial sector, focusing the attention on their potential application in the biomedical sector (Peponi, Navarro-Baena, \& Kenny, 2014; Yahia, 2015). SMPs have the capacity to memorize their original shape after being deformed in a temporary shape under the application of external stimulus, such as temperature, humidity, pH, light, etc. (Olalla, Sessini, Torres, \& Peponi, 2016). These shape changes are achieved throughout the "programming" and the "recovery" stages, regulated by the external stimulus (Peponi, Arrieta, Mujica-Garcia, \& López, 2016). In the "programming" stage, the material is deformed and fixed in a "temporary shape". Then, upon the application of an external stimulus, the material recovers its initial shape throughout the "recovery" stage (Chan et al., 2016). One of the most used stimuli is the temperature, therefore, thermally-activated SMPs have to be heated above their characteristic transition temperature ( $\left.\mathrm{T}_{\text {trans }}\right)$ to induce their shape change (Peponi et al., 2017).

SMPs can be applied in several fields including biomedical applications. However, when SMPs are used for biomedical applications, two key points have to be considered. From one hand, the materials used need to respond to biocompatibility, non-toxicity, 
(C) <2017>. This manuscript version is made available under the CC-BY-NC-ND 4.0 license http://creativecommons.org/licenses/by-nc-nd/4.0/

51 biodegradability, sterilizability and specific mechanical properties (Ward Small,

52 Singhal, Wilson, \& Maitland, 2010). As example, biodegradable polymeric materials are being investigated in developing medical devices such as temporary biological wound dressing materials, temporary prostheses, three-dimensional porous structures as scaffolds for tissue engineering and for drug delivery in pharmacological applications (Arockianathan, Sekar, Kumaran, \& Sastry, 2012; Nair \& Laurencin, 2007). From the other hand, it is necessary to use a stimulus compatible with the human body (Chan et al., 2016; Lendlein, Behl, Hiebl, \& Wischke, 2010). So, when working with thermallyactivated SMPs for biomedical applications, a $\mathrm{T}_{\text {trans }}$ close to body temperature is required (Lendlein et al., 2010). In order to design SMPs with $\mathrm{T}_{\text {trans }}$ close to body temperature it is possible playing with their chemical composition or by adding nanofillers able to modify their thermal response (Behrens \& Appel, 2016). However, moisture-activation of SMPs can be a good alternative as stimuli-responsive materials for biomedical applications (Chen, Hu, Yuen, \& Chan, 2009; Sessini et al., 2016). Further investigations showed that the hydrogen bonding is the key player for the humidity activation as well as water absorbed in the polymer plays a main role in the shape recovery process (Zhang, Wang, Zhong, \& Du, 2009). Therefore, in order to develop humidity-activated SMPs it is possible to use polymers with functional groups able to be involved in hydrogen bonding with water molecules or it is possible to use hydrophilic components.

Thus considering all these properties, biodegradability, hydrophilicity and biocompatibility, starch can be considered as an excellent material for the design of humidity-responsive SMPs for biomedical application. Starch, in fact, is a low cost polysaccharide, abundantly available in nature and one of the cheapest biodegradable polymers. It is produced by agricultural plants in the form of granules, which are hydrophilic (Raquez et al., 2008). Starch is mainly extracted from potatoes, corn, wheat, 
(C) <2017>. This manuscript version is made available under the CC-BY-NC-ND 4.0 license http://creativecommons.org/licenses/by-nc-nd/4.0/ rice, etc. It is composed of amylose (poly- $\alpha-1,4-\mathrm{D}$-glucopyranoside), a linear polymer and amylopectin (poly- $\alpha-1,4-\mathrm{D}$-glucopyranoside and $\alpha$-1,6-D-glucopyranoside), a branched polymer (Lourdin et al., 2015). To extend the starch functionalities, several plants have been modified in their starch biosynthesis pathway to modulate the amount of amylose of starch granules (Firouzabadi, F. N., et al., 2007). In other cases starches are modified in their waxy form, for example characterized by a rich content of amylopectin (> 99\%) to be used for the synthesis of starch nanocrystals, SNCs. (Bemiller, J. N., 1997). Therefore, starch can be used as polymer matrix in form of thermoplastic starch (TPS) by gelatinization of native starch (Averous, 2004) as well as nanofillers in form of starch nanocrystals, SNCs (Angellier, Choisnard, MolinaBoisseau, Ozil, \& Dufresne, 2004). The glass transition temperature $\left(\mathrm{T}_{\mathrm{g}}\right)$ of starch is strongly affected by the relative humidity $(\mathrm{RH})$ at which it is stored showing either a glass-like rigid and fragile mechanical behavior, or a rubber-like behavior (Lourdin, Coignard, Bizot, \& Colonna, 1997). However, the brittleness of starches is frequently overcome by the addition of plasticizers to get the flexibility required for film applications (Jiménez, Fabra, Talens, \& Chiralt, 2012). Among them, glycerol is a natural plasticizer widely used to develop TPS by reducing intra and intermolecular hydrogen bonds (Arrieta, Peltzer, del Carmen Garrigós, \& Jiménez, 2013; Averous, 2004; Jiménez et al., 2012). In the literature there are reports of different biomedical applications of biodegradable starch-based films as SMPs, such as shape-memory resorbable materials (Beilvert et al., 2014), temporary biological wound dressing materials (Arockianathan, Sekar, Kumaran, \& Sastry, 2012), scaffolds for bone tissue engineering applications (Martins et al., 2012) and drug delivery systems (Schmitt et al., 2015). However, preliminary studies on shape memory effects on starch-based materials are presented by Chaunier et al. (Chaunier \& Lourdin, 2009) in 2009 reporting an example of dual-shape capability of potato starch and by Véchambre et al. (Véchambre, 
(C) <2017>. This manuscript version is made available under the CC-BY-NC-ND 4.0 license http://creativecommons.org/licenses/by-nc-nd/4.0/

103 Chaunier \& Lourdin, 2010) in 2010, in which they studied the shape memory response 104 of extruded potato starch triggered by humidity.

105 In order to improve its properties starch can be modified by adding nanofillers obtaining

106 nanocomposites. In general, the addition of nanofillers to a polymer matrix increases its

107 mechanical strength and stiffness and sometimes can generate functional properties,

108 originating from the synergetic effect between both components (Peponi, Puglia, Torre,

109 Valentini, \& Kenny, 2014). Among bionanofillers, special attention has been paid to

110 SNCs (Lin, Huang, Chang, Anderson, \& Yu, 2011).

111 Green tea polyphenols, in particularly catechin (Cat), have gain interest owing to their

112 multiple biological effects due to their strong antioxidant capacity (Castro López et al.,

113 2012). Catechin is also interesting from a processing point of view since their

114 antioxidant activity protects the polymer matrices during thermal and thermomechanical

115 processing (Arrieta et al., 2014). Moreover, catechin can be used to improve shape

116 memory response of polymeric matrices (Arrieta, Sessini \& Peponi, 2017).

117 In our previous work (Sessini, Arrieta, Kenny, \& Peponi, 2016) we reported the

118 processing of gelatinized starch-based films filled with SNCs and catechin as

119 antioxidant agent for edible films. It was observed that for film manufacturing the

120 inherent brittleness of starch can be overcome by the addition of $35 \mathrm{wt} \%$ of glycerol as

121 plasticizer (S-Gly35). Additionally, we observed that the novel combination of

122 plasticized starch compounded with both SNCs and Cat leads to materials with

123 enhanced thermal and mechanical performance.

124 Based on these previous results, the main objective of the present work is to design high

125 performance humidity-activated shape memory starch-based films, for potential

126 biomedical applications. With this purpose, the humidity-activated shape memory

127 behavior was characterized for neat starch plasticized with $35 \%$ of glycerol and its

128 filled counterparts. In order to know the parameters to fix the temporary shape and to 
(C) <2017>. This manuscript version is made available under the CC-BY-NC-ND 4.0 license http://creativecommons.org/licenses/by-nc-nd/4.0/

129 recover the original shape, the moisture loss as well as the moisture absorption was

130 studied evaluating also the effect of the incorporation of both SNCs and catechin on the

131 humidity-activated shape memory properties of plasticized starch-based films.

132 Moreover, the effectiveness of catechin to increase the polymer stability under oxidative

133 atmosphere and the thermo-mechanical relaxation of all the starch-based materials were

134 studied in order to characterize their thermal properties.

\section{2. Materials and Methods}

136 2.1 Materials

137 Native potato starch (moisture content of $12 \%$ and amylose content of $18-21 \%$ ) was

138 kindly supplied by Novamont. Glycerol and catechin dehydrate were purchased from

139 Panreac Quimica (PRS) and Sigma-Aldrich, respectively. Waxy maize starch (N200)

140 used to synthesize the SNCs, was supplied by Roquette Laisa (Spain). Sulfuric acid

$141\left(\mathrm{H}_{2} \mathrm{SO}_{4}\right)$ was purchased from Sigma-Aldrich. SNCs were synthesized by acid hydrolysis

142 as reported in our previous work (Sessini et al., 2016). In brief, waxy maize starch was

143 dispersed in an aqueous solution of $\mathrm{H}_{2} \mathrm{SO}_{4}$ and heated at $40{ }^{\circ} \mathrm{C}$ under continuous

144 mechanical stirring $(100 \mathrm{rpm})$ for 5 days. The final suspensions were washed by

145 successive centrifugations in distilled water $(10,000 \mathrm{rpm}$ for 10 minutes) until reaching

146 neutral $\mathrm{pH}$ and then, it was filtered and stored at $4{ }^{\circ} \mathrm{C}$.

$147 \quad 2.2$ Film preparation

148 The starch-based films were obtained by gelatinization of starch/water/glycerol

149 dispersion (Sessini et al., 2016). Briefly, TPS was successfully obtained by

150 gelatinization of an aqueous dispersion of 1 wt $\%$ of potato starch and 35 wt $\%$ of

151 glycerol relative to the mass of starch. The dispersion was gelatinized at $80{ }^{\circ} \mathrm{C}$ during 15

152 min under continuous stirring. Starch solution, was cast over polystyrene petri dish in a 
(C) <2017>. This manuscript version is made available under the CC-BY-NC-ND 4.0 license http://creativecommons.org/licenses/by-nc-nd/4.0/

153 ventilated oven at $35^{\circ} \mathrm{C}$ for $24 \mathrm{~h}$ to obtain films with a thickness of about $100 \mu \mathrm{m}$. The

154 obtained unfilled film was named S-Gly35. The polymeric matrix was reinforced by

155 adding $1 \mathrm{wt} \%$ (relative to the mass of starch) of catechin (S-Gly35-Cat) and SNCs (S-

156 Gly35-SNC), respectively. Moreover, the synergetic effect of both catechin and SNCs

157 was evaluated in the starch-based films by adding together catechin and SNCs, both at 1

158 wt \% relative to the mass of starch, obtaining the sample named S-Gly35-Cat-SNC.

159 2.3 Characterization Techniques

160 Before characterization, all the starch-based films were stored for one week at $50 \% \mathrm{RH}$.

161 The SNCs dispersion into the polymer matrix was studied by Field Emission Scanning

162 Electron Microscope (FE-SEM, Hitachi S8000). The cryo-fracture surfaces of the

163 starch-based films filled with SNCs were observed. The films were previously frozen

164 using liquid $\mathrm{N}_{2}$ and then cryo-fractured. All the samples were chrome coated by an

165 automatic sputter coater Quorum Tech Q 150T ES previously to be observed by FE166 SEM.

167 Differential Scanning Calorimetry (DSC) analysis was performed in a Mettler Toledo

168 DSC822e instrument under oxygen atmosphere $(30 \mathrm{~mL} / \mathrm{min})$. Samples were heated

169 from 30 to $300{ }^{\circ} \mathrm{C}$ at a heating rate of $10^{\circ} \mathrm{C} \mathrm{min}-1$ to determine the oxidation induction

170 time (OIT) as well as the temperature at which a rapid increase in the rate of oxidation

171 was observed (onset oxidation temperature, OOT). OIT and OOT values were

172 calculated by extrapolating the tangent drawn on the steepest slope of exothermic

173 reaction, which corresponds to the degradation, in the baseline (Erhan, Sharma, \&

174 Perez, 2006).

175 Dynamic Mechanical Thermal Analysis (DMTA) of the samples was carried out using a

176 DMA Q800 from TA Instrument in film tension mode with an amplitude of $5 \mu \mathrm{m}$, a

177 frequency of $1 \mathrm{~Hz}$, a force track of $125 \%$ and a heating rate of $2{ }^{\circ} \mathrm{C} \cdot \mathrm{min}^{-1}$. The samples 
(C) <2017>. This manuscript version is made available under the CC-BY-NC-ND 4.0 license http://creativecommons.org/licenses/by-nc-nd/4.0/

178 were cut from casted films into rectangular specimens of approximately $20 \mathrm{~mm}$ x $6 \mathrm{~mm}$ $179 \times 0.10 \mathrm{~mm}$.

180 Surface wettability of the starch-based films was studied through static water contact 181 angle (WCA) measurements using a KSV Theta goniometer. The volume of the droplets 182 was controlled to be about $7.0 \mu \mathrm{L}$ and a charge coupled device camera was used to 183 capture the images of the water droplets for the determination of the contact angles. The contact angle was determined by randomly putting 4 drops of distilled water with a syringe onto the film surfaces and the average values were used.

Moisture absorption was tested at room temperature (RT) after specimens were dried in

187 a dry chamber $(\mathrm{RH} \leq 10 \%)$. The samples were put on a humidity chamber at $\mathrm{RH}=72$

$188 \%$. Saturated salt solutions were used to provide specific relative humidity. Weight 189 percentage of specimen was weighted after each 5 min firstly, and then the moisturizing 190 time increased gradually when its absorption speed was slow (Chen et al., 2009; Vogt, 191 Soles, Lee, Lin, \& Wu, 2005). Finally, the dependency of moisture absorption on time 192 was obtained. The same method was used to test the dependency of moisture loss vs 193 time. The specimens were put on a dry chamber $(\mathrm{RH} \leq 10 \%)$ at $\mathrm{RT}$ until reach the 194 equilibrium.

195 Humidity-mechanical cyclical experiments were carried out by bending test. The 196 programming stage was performed in a dry chamber $(\mathrm{RH} \leq 10 \%)$ at $\mathrm{RT}$, then the 197 recovery stage was achieved in a humidity chamber $(\mathrm{RH}=72 \%)$ at $\mathrm{RT}$. The samples 198 were cut from the casted films into rectangular specimens of approximately $40 \mathrm{~mm} \times 15$ $199 \mathrm{~mm} \times 0.10 \mathrm{~mm}$.

200 The shape recovery ratio $\left(\mathrm{R}_{\mathrm{r}}\right)$ was calculated from the ratio of the different angles before 201 and after recovery using the recovered angles $\left(\Theta_{\mathrm{r}}\right)$ and the deformed angles $\left(\Theta_{\mathrm{d}}\right)$ in the 202 temporary shape, as reported in the equation below: 
(C) <2017>. This manuscript version is made available under the CC-BY-NC-ND 4.0 license http://creativecommons.org/licenses/by-nc-nd/4.0/

$203 \quad R_{r}(\%)=\frac{\left(\theta_{d}-\theta_{r}\right)}{\theta_{d}} \times 100$

204 The shape fixity ratio $\left(\mathrm{R}_{\mathrm{f}}\right)$ can be calculated from the ratio of the fixed angle $\left(\Theta_{\mathrm{f}}\right)$ and

205 the $\Theta_{\mathrm{d}}$ as shown in the follow equation:

$206 \quad R_{f}(\%)=\frac{\theta_{f}}{\theta_{d}} \times 100$

Equation (2)

207 The measure of the bending test angles has been carried out through an open source

208 image-processing program, ImageJ. The measures have been taken for triplicate in order

209 to calculate a standard deviation. Scheme 1 indicates the bending test procedure for

210 studying the shape memory behaviour of the materials, indicating the recovered and

211 deformed angles as well as the humidity corresponding to each phase of the

212 programming and recovery analysis. 
(C) <2017>. This manuscript version is made available under the CC-BY-NC-ND 4.0 license http://creativecommons.org/licenses/by-nc-nd/4.0/
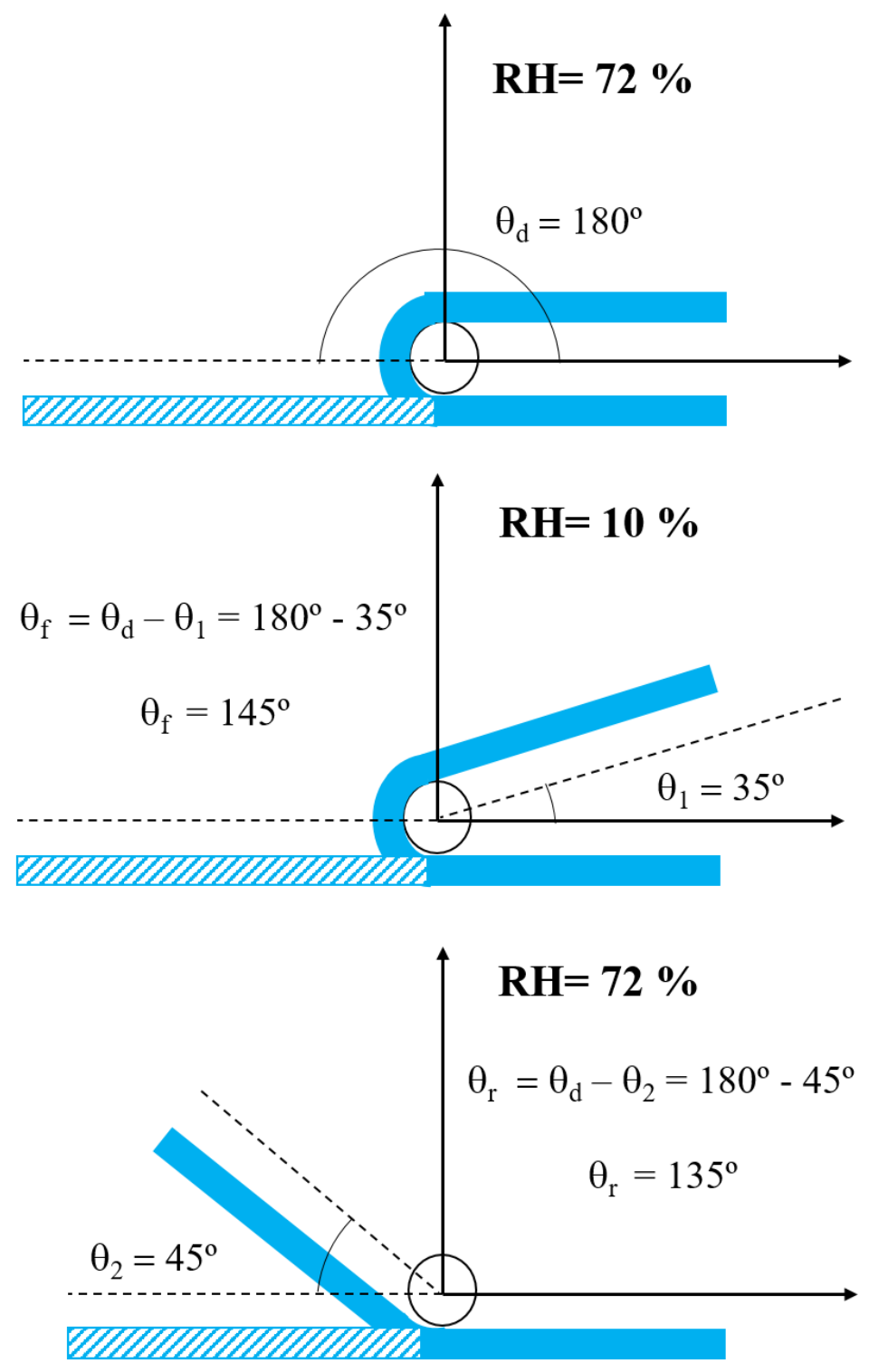

214 Scheme 1. Bending test procedure for studying the shape memory behaviour of the materials, indicating the recovered and deformed angles as well as humidity.

\section{3. Results and Discussion}

217 The cryo-fractured starch-based film surfaces (surface of rupture on the thickness of the

218 film) were studied with FE-SEM in order to visualize the SNCs dispersion into the 219 starch matrix. Figure 1 shows the cryo-fractured surface of the samples reinforced with 220 SNCs, i.e. S-Gly35-SNC and S-Gly35-Cat-SNC. SNCs were visible in the FE-SEM 
(C) <2017>. This manuscript version is made available under the CC-BY-NC-ND 4.0 license http://creativecommons.org/licenses/by-nc-nd/4.0/

221 images, confirming their good dispersion into the plasticized starch-based film (See 222 arrows in Figure 1).

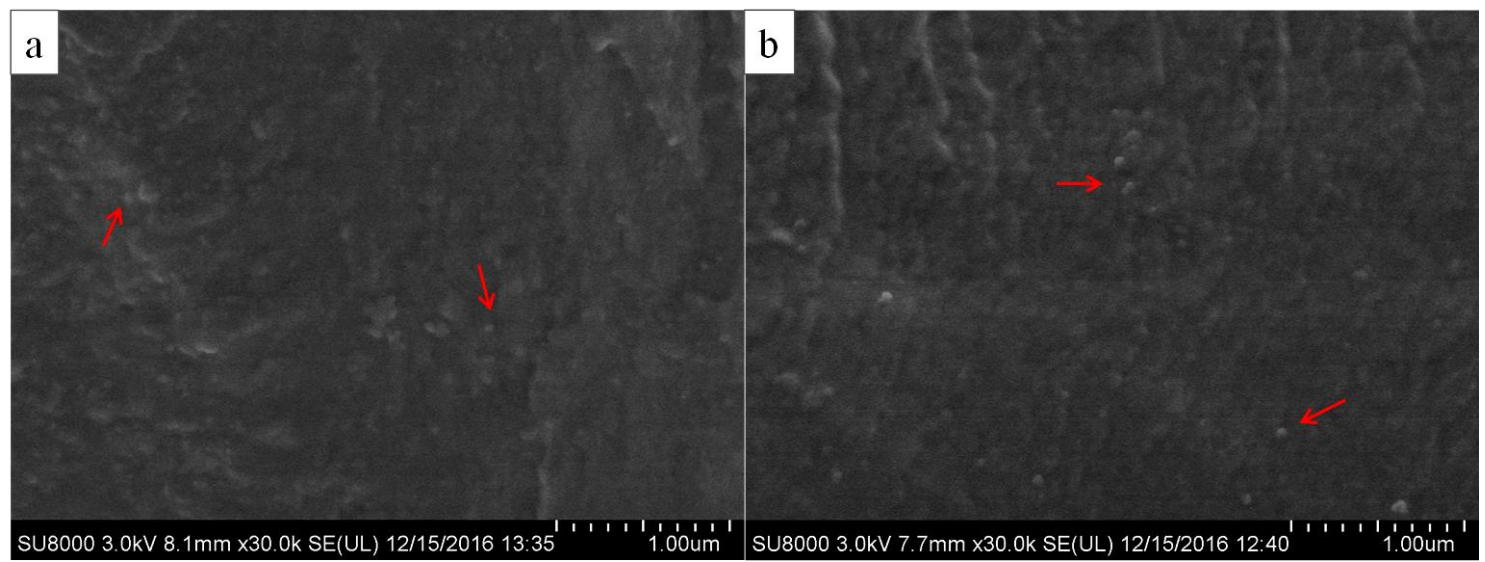

Figure 1. FE-SEM images of the cryo-fractured surface of the starch-based materials reinforced with SNCs; a) S-Gly35-SNC and b) S-Gly35-Cat-SNC.

In order to study the main thermo-mechanical relaxation of our systems, DMTA was performed. The evolution of the storage modulus ( $\left.E^{\prime}\right)$, loss modulus (E") and damping factor $(\tan \delta)$ as a function of temperature was measured over the temperature range of $80{ }^{\circ} \mathrm{C}$ to $100{ }^{\circ} \mathrm{C}$ and the results are presented in Figure 2 . At temperature $-80{ }^{\circ} \mathrm{C}$, all the

230 starch-based films exhibit high storage modulus values, indicating the rigidity of the

231 freeze structure below $\mathrm{T}_{\mathrm{g}}$. The storage modulus falls in two steps, the first between -80 and $-30{ }^{\circ} \mathrm{C}$ and the second one, less evident, between -30 and $40{ }^{\circ} \mathrm{C}$ with the corresponding peaks in the loss modulus curve (Figure 2.b) around $-47^{\circ} \mathrm{C}$ and $21{ }^{\circ} \mathrm{C}$,

234 respectively. It was previously reported in the literature that for starch-based materials

235 constituted by the three-constituent system such as water-glycerol-starch, the roles of 236 the two plasticizers (glycerol and water) are dependent on their respective concentration

237 (Lourdin, Bizot, \& Colonna, 1997). In fact, depending on the plasticizer content, starch 238 can show two different structural relaxations corresponding to a non-homogeneous 239 material constituted by two different phases, a glycerol-rich phase and a starch-rich 240 phase (Liu, Bhandari, \& Zhou, 2006). 
(C) <2017>. This manuscript version is made available under the CC-BY-NC-ND 4.0 license http://creativecommons.org/licenses/by-nc-nd/4.0/
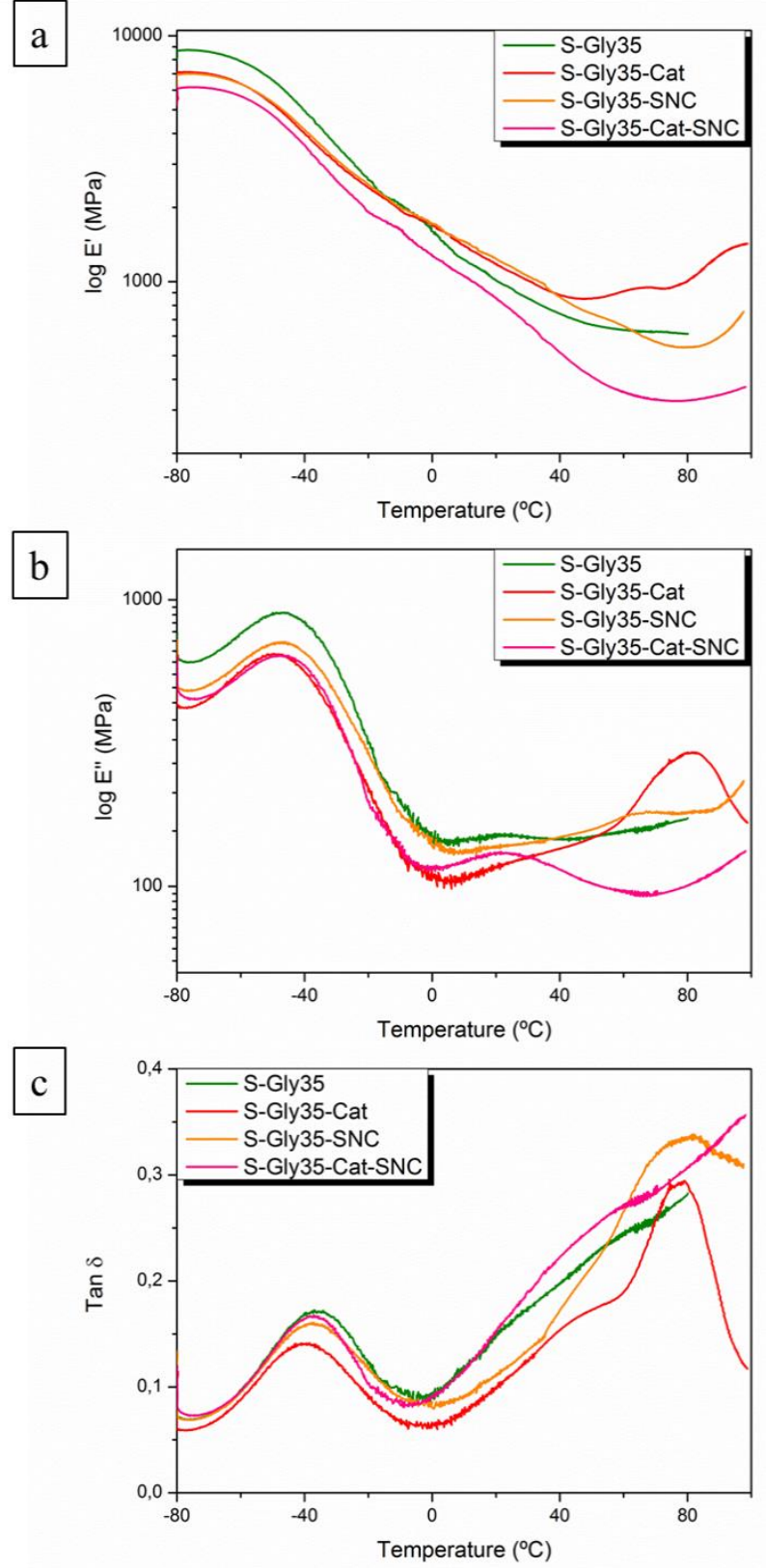

242 Figure 2. Dynamic mechanical thermal analysis, a) storage modulus, b) loss modulus and c) damping factor, for all the starch-based films.

244 In our case, the results observed in Figure 2.b suggest that by using 35 wt $\%$ of glycerol,

245 two glass transitions of a phase-separated system on all the starch-based film curves can

246 be observed. The first peak in the loss modulus curves (Figure 2.b), named $\beta$ relaxation,

247 is due to the glycerol-rich phase. The second peak in the loss modulus curve (Figure

248 2.b) around $21^{\circ} \mathrm{C}$, named $\alpha$ relaxation, was attributed to the $\mathrm{T}_{\mathrm{g}}$ of starch, confirming 249 previous results reported in literature (Forssell, Mikkilä, Moates, \& Parker, 1997). As it 
(C) <2017>. This manuscript version is made available under the CC-BY-NC-ND 4.0 license http://creativecommons.org/licenses/by-nc-nd/4.0/

250 is shown in Figure 2.b and c, it can be concluded that the fillers does not disturb the 251 mobility of glycerol-rich phase. On the contrary, when the SNCs were added into the 252 starch-based matrix, the $\alpha$ relaxation is found to increase and to shift to higher values of 253 temperature, even more when only Cat were added. This is an indication that the 254 presence of the filler hinders the molecular mobility of amylopectin chains, in agreement with the results obtained also by Viguié et al. (Viguié, Molina-Boisseau, \& Dufresne, 2007) for plasticized waxy maize starch reinforced with SNCs. Viguié et al. reported that this phenomenon is most probably ascribed to a direct contact between amylopectin-rich domains of the matrix and starch nanocrystals, and to the formation of strong interactions between both components due to hydrogen bonding (Viguié et al., 2007). Thus, in our case, SNCs and particularly Cat (S-Gly35-SNC and S-Gly35-Cat), hindered the molecular mobility of amylopectin chains probably due to the formation of hydrogen bonding. In the case of S-Gly35-Cat-SNC, where $1 \%$ of both, Cat and SNCs, were added into the starch-based films, $\alpha$ relaxation temperature evidently decreased compare to the other filled films.

The temperatures of relaxation observed are summarized on Table 1.

Table 1: Summary of the relaxation temperatures taken from loss modulus diagram.

\begin{tabular}{|l|l|l|}
\hline Sample & $\beta$-relaxation $\left({ }^{\circ} \mathrm{C}\right)$ & $\alpha$-relaxation $\left({ }^{\circ} \mathrm{C}\right)$ \\
\hline S-Gly35 & -45 & 21 \\
\hline S-Gly35-Cat & -49 & 79 \\
\hline S-Gly35-SNC & -46 & 64 \\
\hline S-Gly35-Cat-SNC & -45 & 25 \\
\hline
\end{tabular}


(C) <2017>. This manuscript version is made available under the CC-BY-NC-ND 4.0 license http://creativecommons.org/licenses/by-nc-nd/4.0/

269 This result suggests that the presence of SNCs probably weakness the interchain 270 interactions between starch matrix and catechin leading to an increase of molecular 271 mobility of amylopectin chains and thus recovering the same mobility of its neat 272 counterpart.

273 Starch-based materials are highly sensitive to humidity and their $\mathrm{T}_{\mathrm{g}}$ decrease upon the

274 water content absorbed into the material. Indeed, the humidity is capable to depress the 275 glass transition of starch below room temperature. Lourdin et al. (Lourdin et al., 1997) reported that the $\mathrm{T}_{\mathrm{g}}$ of potato starch occurs below or above room temperature as a

277 function of both the plasticizer and the water content. They showed that for potato 278 starch with $35 \mathrm{wt} \%$ of glycerol, a content of water higher than 13 wt $\%$ is necessary to 279 obtain a $\mathrm{T}_{\mathrm{g}}$ below room temperature. Therefore, humidity is used as external stimulus 280 needed by these starch-based materials to present humidity-activated shape memory 281 behavior at room temperature due to the plastificant effect of water. At $\mathrm{RH}=72 \%$ the materials present a rubber-like behaviour, thus it was possible to modify their shape and to fix the temporary shape only reducing the $\mathrm{RH}$. In fact at $\mathrm{RH}=10 \%$ the materials

284 present a glass-like rigid behavior and they were capable to fix their temporary shape.

285 Finally the recovery was activated with humidity $(\mathrm{RH}=72 \%)$. The materials became rubber-like again and the forces stored into the material during the programming, drove

287 the recovery process. For that reason, the shape memory mechanism proposed here 288 depends on the plasticizing effect of humidity on starchy materials.

289 Therefore, in order to define how many minutes are needed to activate both 290 programming and recovery steps in the humidity-mechanical cycles used for the 291 evaluation of the humidity-activated shape memory behavior, the dependency of 292 moisture loss as well as of its absorption as a function of time were studied at RT. 293 Figure 3.a and $\mathrm{b}$ present the dependencies of the moisture loss (fundamental for the 294 temporary shape fixity) and the moisture absorption (fundamental for the original shape 
(C) <2017>. This manuscript version is made available under the CC-BY-NC-ND 4.0 license http://creativecommons.org/licenses/by-nc-nd/4.0/ recovery) with time for all the starch-based films. In Figure 3.a, it can be observed that

296 all the starch-based films lost the moisture very quickly within the first $90 \mathrm{~min}$, showing

297 the same slope of the moisture loss curves for all the samples analyzed. Then, they tend

298 to reach their equilibrium state after $300 \mathrm{~min}$. Whereas, in S-Gly35-SNC the wt \% of

299 moisture lost was pretty much the same of its neat counterpart (S-Gly35). In the case of

300 S-Gly35-Cat the wt \% of moisture lost is lower than S-Gly35, and even more for S-

301 Gly35-Cat-SNC. The same trend is shown in Figure 3.b for the moisture absorption.

302 Indeed S-Gly35 and S-Gly35-SNC followed the same trend of moisture absorption,

303 absorbing around 19 wt \% of water at the equilibrium, 16 wt \% for S-Gly35-Cat and 13

304 wt \% for S-Gly35-Cat-SNC have been obtained. The results showed that the presence of

305 catechin in the starch matrix decreased the total wt $\%$ of moisture lost and absorbed,

306 decreasing evens more with the presence of SNCs. Considering the high amount of

307 hydroxyl groups on catechin and SNCs surfaces, it is expected that they will interact

308 with water since the amount of water uptake is directly related with their polar free

309 fraction able to interact with water (Arrieta et al., 2014).

310 Nevertheless, in the case of S-Gly35-Cat-SNC, the well interaction established between

311 catechin and SNCs, leaded to less available -OH groups of both materials to interact

312 with water, and thus S-Gly35-Cat-SNC formulation shows the lowest water absorption. 
(C) <2017>. This manuscript version is made available under the CC-BY-NC-ND 4.0 license http://creativecommons.org/licenses/by-nc-nd/4.0/
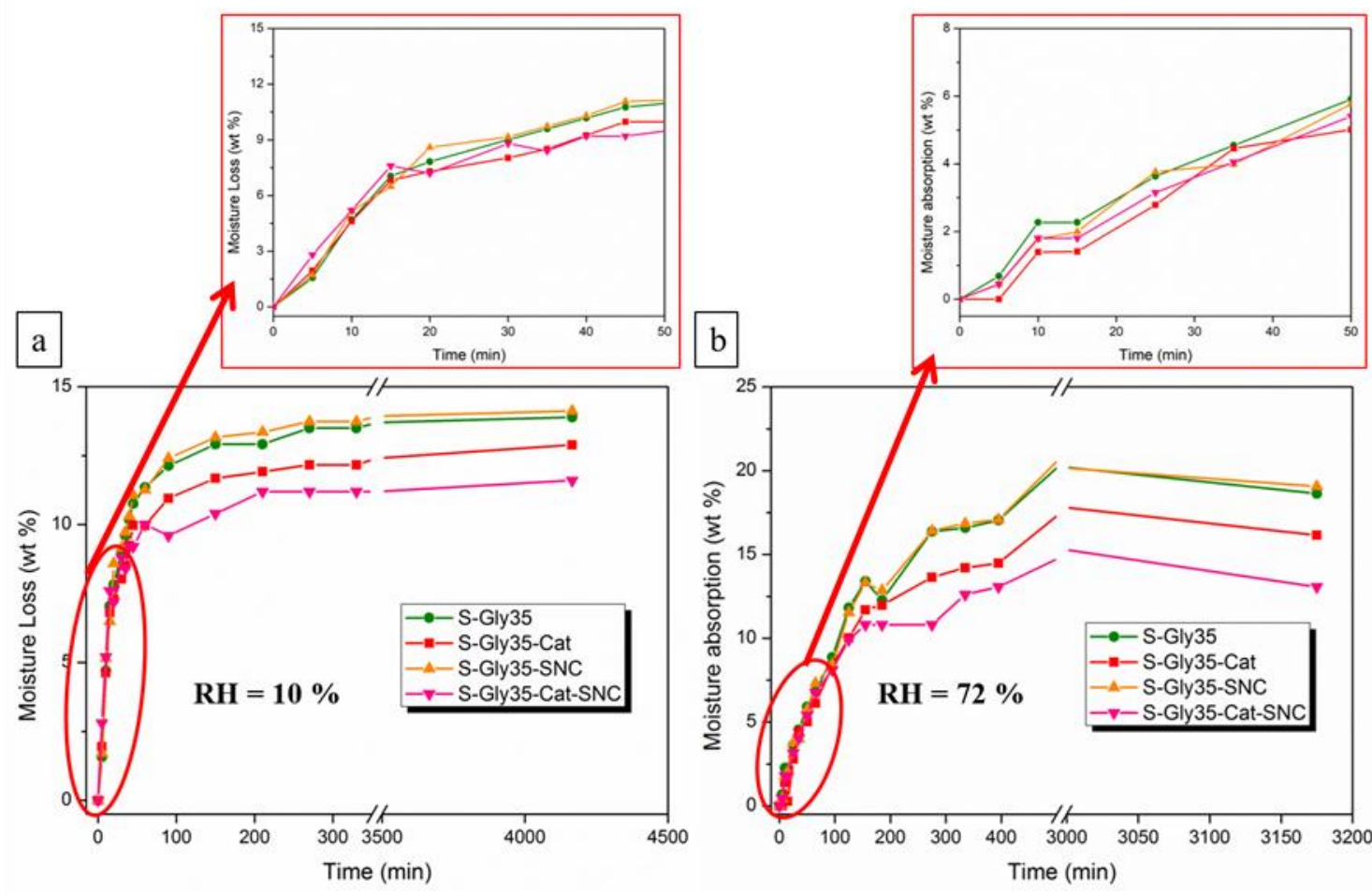

Figure 3. Dependencies on time of: a) moisture loss and b) moisture absorption.

315 The less water absorption was followed by the S-Gly35-Cat starch-based film since

316 their -OH groups can interact better with plasticized starch matrix than SNCs, as it was

317 already commented in DMTA results. For all starch-based films the slop of moisture

318 loss (Figure 3.a) was much higher than that of moisture absorption (Figure 3.b) showing

319 a faster kinetic for moisture loss process. In fact, in Figure 3.b, it can be observed that

320 all the starch-based films absorbed much moisture within the first $150 \mathrm{~min}$ and then

321 they tend to reach their saturated state after 450 minutes though they reach a middle maximum due to the swelling-deswelling phenomenon known as "overshooting effect"

323 (Yin, Ji, Dong, Ying, \& Zheng, 2008; Zhu, Ma, Wang, Zhang, \& Zhang, 2016), then

324 they reached the equilibrium.

325 However, in order to study the shape memory behaviour it is not necessary that the samples reach their equilibrium state. And from the zoom of both graphics of the 
(C) <2017>. This manuscript version is made available under the CC-BY-NC-ND 4.0 license http://creativecommons.org/licenses/by-nc-nd/4.0/ about 20 minutes. For this reason a time of 40 minutes has been choose for studying the shape memory response of these starch-based materials.

330 Therefore, we determined the conditions to be used for the humidity-mechanical cycles 331 performed in the bending test configuration at RT:

$332-$ Programming: conditioning the sample at $\mathrm{RH}=72 \%$ for 40 minutes and then bending the samples under humidity conditions. Drying the samples at $\mathrm{RH} \leq 10$ temporary shape and recovering the original shape at $\mathrm{RH}=72 \%$ for 40 minutes.

337 These experimental conditions confirm that a time of $40 \mathrm{~min}$ is enough to change the

338 physical behaviour of the starch-based material. In order to evaluate their shapememory response, four different humidity-mechanical cycles were completed for each

340 sample. In Figure 4, an example of humidity-mechanical bending cycle for all the 341 materials is reported.

342 The $R_{r}$ and $R_{f}$ values obtained for each cycle of the starch-based films are reported in

343 Table 2. The presence of both fillers, SNCs and Cat, produced a significant increase on

344 the shape recovery ratio showing that the presence of particles gives higher stiffness to 345 the systems allowing the better recovery of their original shape.

346 Table $2 . R_{r}$ and $R_{f}$ values for all the humidity-activated bending cycles performed for all the samples studied.

\begin{tabular}{l|l|l|l|l|l|l|l|l}
\hline Sample & \multicolumn{5}{c|}{$R_{\text {r (\%) }}$} & \multicolumn{5}{c}{$R_{f}(\%)$} \\
\hline \multicolumn{1}{r|}{ Cycle } & 1 & 2 & 3 & 4 & 1 & 2 & 3 & 4 \\
& & & & & & & & \\
\hline S-Gly35 & $95 \pm 2$ & $91 \pm 1$ & $89 \pm 1$ & $89 \pm 1$ & $96 \pm 1$ & $99 \pm 1$ & $98 \pm 1$ & $94 \pm 1$ \\
\hline S-Gly35-Cat & $98 \pm 1$ & $99 \pm 1$ & $99 \pm 1$ & $99 \pm 1$ & $97 \pm 1$ & $96 \pm 1$ & $96 \pm 2$ & $98 \pm 1$ \\
& & & & & & & & \\
\hline
\end{tabular}


(C) <2017>. This manuscript version is made available under the CC-BY-NC-ND 4.0 license http://creativecommons.org/licenses/by-nc-nd/4.0/

\begin{tabular}{l|c|c|c|c|c|c|c|c}
\hline S-Gly35-SNC & $99 \pm 1$ & $98 \pm 1$ & $99 \pm 1$ & $98 \pm 1$ & $98 \pm 1$ & $97 \pm 1$ & $98 \pm 1$ & $97 \pm 1$ \\
\hline S-Gly35-Cat-SNC & $95 \pm 1$ & $97 \pm 1$ & $96 \pm 1$ & $98 \pm 1$ & $98 \pm 1$ & $96 \pm 1$ & $96 \pm 1$ & $93 \pm 1$ \\
\hline
\end{tabular}




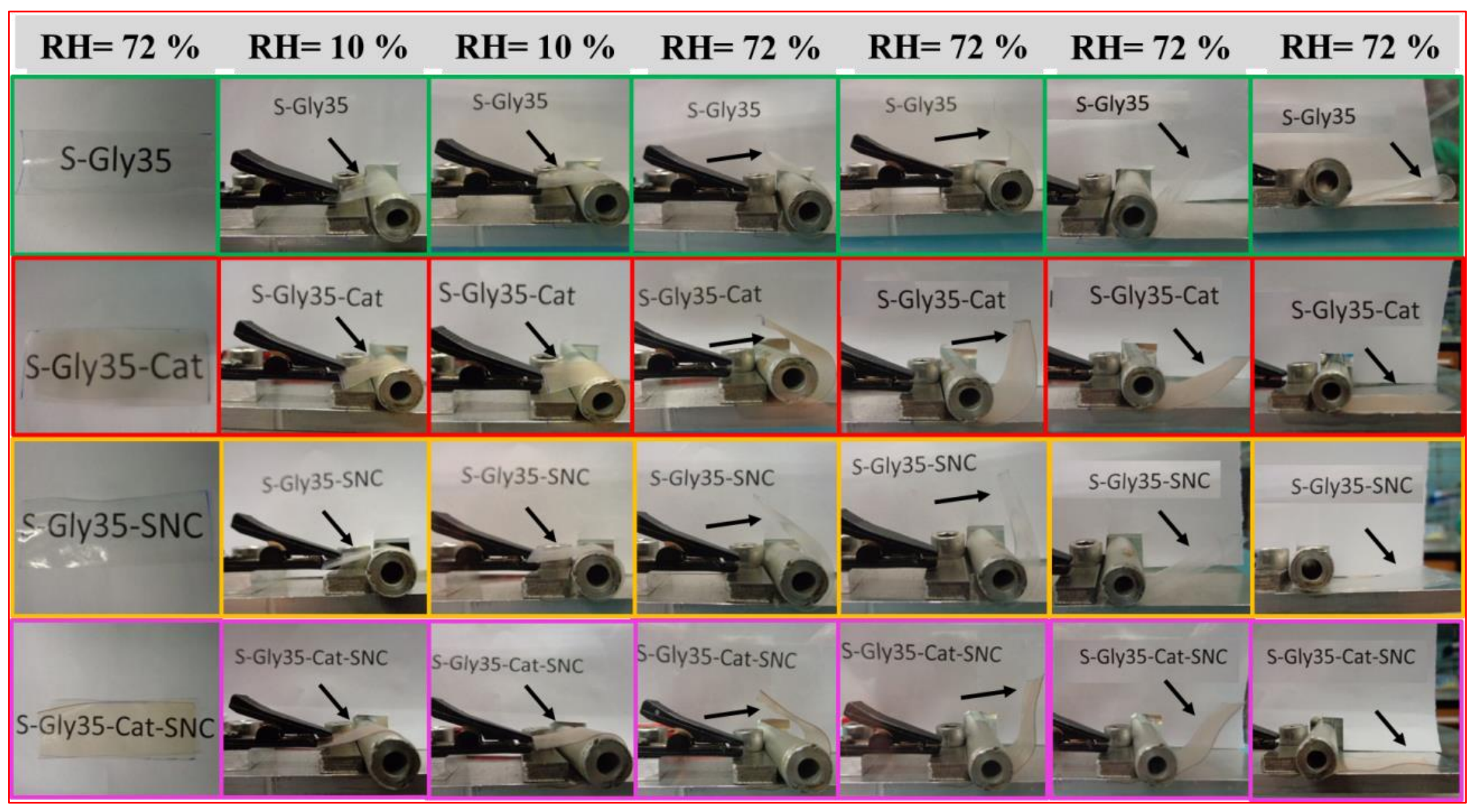

Figure 4. Example of humidity-activated bending cycles for all the starch-based films. 
(C) <2017>. This manuscript version is made available under the CC-BY-NC-ND 4.0 license http://creativecommons.org/licenses/by-nc-nd/4.0/

In Table 2 it is easy to note that the obtained $R_{f}$ and $R_{r}$ values reflect the excellent ability to both, fix the temporary and recover the original shape, respectively, even for the neat starch-based film, S-Gly35. The $\mathrm{R}_{\mathrm{r}}$ values increased for S-Gly35-Cat, S-Gly35SNC and S-Gly35-Cat-SNC, reaching values close to $100 \%$, increasing the recovery ability of the neat matrix. Moreover, $\mathrm{R}_{\mathrm{f}}$, close to $100 \%$ for the neat matrix, did not change with the addition of the fillers to the matrix.

In order to study the possible biomedical application of these shape memory starchbased materials, the wettability and hydrophobic characteristics of their surfaces were determined from WCA measurements. It is known that the WCA is dependent on the cohesive and adhesive molecular forces within water and between the solid surface and water, respectively. A WCA higher than $65^{\circ}$ is typical used as a threshold for hydrophobic surfaces, meanwhile WCA lower than $65^{\circ}$ are related to hydrophilic surfaces (Arrieta et al., 2014; Vogler, 1998).

Surface wettability of artificial materials for biomedical applications is one of the most important factors affecting the cells adhesion. In fact, cells adhesion is not good on surfaces having too low or too high wettability (Wang et al., 2012; Yuan et al., 2013). In particular, with respect to surface wettability of polymeric materials, cells effectively adhere onto polymer surfaces presenting moderate wettability that is with WCA in the range of $40-70^{\circ}$ (Arima \& Iwata, 2007). In Figure 5, the WCA values for all the starchbased materials are reported. S-Gly35 showed a WCA of $83 \pm 4^{\circ}$, while the other films showed lower WCA. This means that the incorporation of SNCs and catechin increases the wettability of the starch-based films. Indeed when SNCs were added to the system, the contact angle decrease until $66 \pm 3^{\circ}$ and when catechin was added a contact angle of $63 \pm 3^{\circ}$ was reported. 
(C) <2017>. This manuscript version is made available under the CC-BY-NC-ND 4.0 license http://creativecommons.org/licenses/by-nc-nd/4.0/

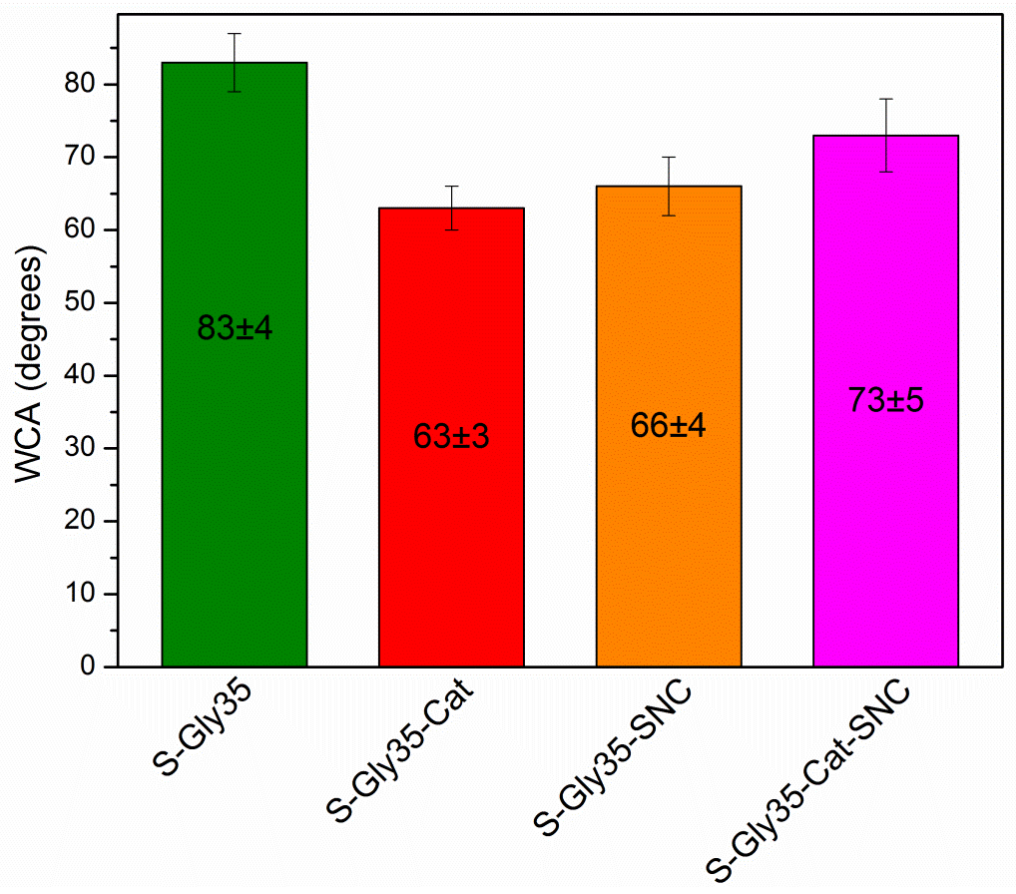

Figure 5. Wettability of all the starch-based films.

The decrease in WCA of the filled films is related with the high amount of $-\mathrm{OH}$ groups of catechin and SNCs whit surface orientation, which interact with the water at the material surfaces leading to more hydrophilic surfaces (M. Arrieta, López, López, Kenny, \& Peponi, 2016). On the contrary, when both particles were incorporated to the starch matrix, the WCA increased compared to the other filled films, but it still decreases compared to its neat counterpart. The higher WCA observed in S-Gly35-Cat$\mathrm{SNC}$ with respect to the other filled films could be related with the fact that some $-\mathrm{OH}$ groups of catechin and SNCs are interacting between them and thus are less available to interact with the water molecules at the material surfaces, thus confirming our previous results. However, it can be concluded that the obtained starch-based films, present the ideal moderate wettability needed for cells adhesion and that they might be use as potential shape-memory materials for biomedical applications. 
(C) <2017>. This manuscript version is made available under the CC-BY-NC-ND 4.0 license http://creativecommons.org/licenses/by-nc-nd/4.0/

\section{Conclusions}

In this work, the humidity-activated shape memory behaviour of starch-based film reinforced with the innovative combination of SNCs and the antioxidant catechin were studied. FE-SEM showed well dispersed SNCs while DSC analysis under oxidative conditions revealed that catechin protect the starch-based matrix against thermooxidation. The addition of both particles to the polymeric matrix produced materials with more hydrophilic surfaces due to the surface orientation of $-\mathrm{OH}$ groups. Meanwhile, the positive interaction between Cat and SNCs into the S-Gly35-Cat-SNC starch-based film leads to a material with reduced moisture loss as well as reduced moisture absorption. The influence of catechin and SNCs addition on their thermal relaxation was studied by DMA and it showed that the combination of both particles probably weakness the interchain interactions between starch and catechin leading to an increase of molecular mobility of amylopectin chains. The plasticizing effect of moisture on starchy materials was the mechanism involved in the humidity-activated shape memory behavior, depressing the glass transition of starch below room temperature. Therefore, actuation of this starch-based material can be achieved at room temperature only using humidity. The obtained $R_{f}$ and $R_{r}$ values reflect the excellent ability to both, fix and recover the temporary and original shape respectively, even for the neat film. The presence of both fillers, SNCs and Cat, produced a significant increase on the shape recovery ratio values allowing a better recuperation of the original shape.

The combination of plasticized starch matrix loaded with both, SNCs and Cat particles, leads to a multifunctional starch-based film with increased hydrophilicity and with humidity-activated shape memory behavior with interest for potential biomedical applications. 
(C) <2017>. This manuscript version is made available under the CC-BY-NC-ND 4.0 license http://creativecommons.org/licenses/by-nc-nd/4.0/

\section{Acknowledgements}

Authors thank Spanish Ministry of Economy and Competitiveness, MINECO, (MAT2013-48059-C2-1-R). M.P.A. and L.P. acknowledge the Juan de la Cierva (FJCI2014-20630) and Ramon y Cajal (RYC-2014-15595) contracts from the MINECO, respectively. Authors thanks also CSIC for the I-LINK project, I-LINK1149.

\section{References}

Angellier, H., Choisnard, L., Molina-Boisseau, S., Ozil, P., \& Dufresne, A. (2004). Optimization of the preparation of aqueous suspensions of waxy maize starch nanocrystals using a response surface methodology. Biomacromolecules, 5(4), $1545-1551$.

Arima, Y., \& Iwata, H. (2007). Effect of wettability and surface functional groups on protein adsorption and cell adhesion using well-defined mixed self-assembled monolayers. Biomaterials, 28(20), 3074-3082.

Arockianathan, P. M., Sekar, S., Kumaran, B., \& Sastry, T. (2012). Preparation, characterization and evaluation of biocomposite films containing chitosan and sago starch impregnated with silver nanoparticles. International journal of biological macromolecules, 50(4), 939-946.

Arrieta, M., López, J., López, D., Kenny, J., \& Peponi, L. (2016). Effect of chitosan and catechin addition on the structural, thermal, mechanical and disintegration properties of plasticized electrospun PLA-PHB biocomposites. Polymer Degradation and Stability, 132, 145-156. 
(C) <2017>. This manuscript version is made available under the CC-BY-NC-ND 4.0 license http://creativecommons.org/licenses/by-nc-nd/4.0/

Arrieta, M. P., Castro-López, M. a. d. M., Rayón, E., Barral-Losada, L. F., LópezVilariño, J. M., López, J., \& González-Rodríguez, M. V. (2014). Plasticized poly (lactic acid)-poly (hydroxybutyrate)(PLA-PHB) blends incorporated with catechin intended for active food-packaging applications. Journal of agricultural and food chemistry, 62(41), 10170-10180.

Arrieta, M. P., Peltzer, M. A., del Carmen Garrigós, M., \& Jiménez, A. (2013). Structure and mechanical properties of sodium and calcium caseinate edible active films with carvacrol. Journal of Food Engineering, 114(4), 486-494.

Arrieta, M. P., Peltzer, M. A., López, J., del Carmen Garrigós, M., Valente, A. J., \& Jiménez, A. (2014). Functional properties of sodium and calcium caseinate antimicrobial active films containing carvacrol. Journal of Food Engineering, 121, 94-101.

Arrieta, M. P., Sessini, V. \& Peponi, L. (2017). Biodegradable poly(ester-urethane) incorporated with catechin with shape memory and antioxidant activity for food packaging. European Polymer Journal, 94, 111-124.

Averous, L. (2004). Biodegradable multiphase systems based on plasticized starch: a review. Journal of Macromolecular Science, Part C: Polymer Reviews, 44(3), 231-274.

Behrens, S., \& Appel, I. (2016). Magnetic nanocomposites. Current opinion in biotechnology, 39, 89-96.

Beilvert, A., Chaubet, F., Chaunier, L., Guilois, S., Pavon-Djavid, G., Letourneur, D., . . . Lourdin, D. (2014). Shape-memory starch for resorbable biomedical devices. Carbohydrate Polymers, 99, 242-248.

Bemiller, J. N. (1997). Starch modification: challenges and prospects. Starch-Stärke, 49(4), 127-131. 
(C) <2017>. This manuscript version is made available under the CC-BY-NC-ND 4.0 license http://creativecommons.org/licenses/by-nc-nd/4.0/

Castro López, M. d. M., Pérez, M. C., García, M. S. D., Vilarino, J. M. L., Rodríguez, M. V. G., \& Losada, L. F. B. (2012). Preparation, evaluation and characterization of quercetin-molecularly imprinted polymer for preconcentration and clean-up of catechins. Analytica chimica acta, 721, 68-78.

Chan, B. Q. Y., Low, Z. W. K., Heng, S. J. W., Chan, S. Y., Owh, C., \& Loh, X. J. (2016). Recent advances in shape memory soft materials for biomedical applications. ACS applied materials \& interfaces, 8(16), 10070-10087.

Chaunier, L., \& Lourdin, D. (2009). The shape memory of starch. Starch/Stärke, 61 (2), 116-118.

Chen, S., Hu, J., Yuen, C.-w., \& Chan, L. (2009). Novel moisture-sensitive shape memory polyurethanes containing pyridine moieties. Polymer, 50(19), 44244428.

Erhan, S. Z., Sharma, B. K., \& Perez, J. M. (2006). Oxidation and low temperature stability of vegetable oil-based lubricants. Industrial Crops and Products, 24(3), 292-299.

Firouzabadi, F. N., Vincken, J. P., Ji, Q., Suurs, L. C., Buléon, A., \& Visser, R. G. (2007). Accumulation of multiple-repeat starch-binding domains (SBD2-SBD5) does not reduce amylose content of potato starch granules. Planta, 225(4), 919933.

Forssell, P. M., Mikkilä, J. M., Moates, G. K., \& Parker, R. (1997). Phase and glass transition behaviour of concentrated barley starch-glycerol-water mixtures, a model for thermoplastic starch. Carbohydrate Polymers, 34(4), 275-282.

Jiménez, A., Fabra, M. J., Talens, P., \& Chiralt, A. (2012). Edible and biodegradable starch films: a review. Food and Bioprocess Technology, 5(6), 2058-2076. 
(C) <2017>. This manuscript version is made available under the CC-BY-NC-ND 4.0 license http://creativecommons.org/licenses/by-nc-nd/4.0/

Lendlein, A., Behl, M., Hiebl, B., \& Wischke, C. (2010). Shape-memory polymers as a technology platform for biomedical applications. Expert Review of Medical Devices, 7(3), 357-379.

Lin, N., Huang, J., Chang, P. R., Anderson, D. P., \& Yu, J. (2011). Preparation, modification, and application of starch nanocrystals in nanomaterials: a review. J. Nanomaterials, 2011, 1-13.

Liu, Y., Bhandari, B., \& Zhou, W. (2006). Glass transition and enthalpy relaxation of amorphous food saccharides: a review. Journal of agricultural and food chemistry, 54(16), 5701-5717.

Lourdin, D., Bizot, H., \& Colonna, P. (1997). “Antiplasticization” in starch+glycerol films? Journal of Applied Polymer Science, 63(8), 1047-1053.

Lourdin, D., Coignard, L., Bizot, H., \& Colonna, P. (1997). Influence of equilibrium relative humidity and plasticizer concentration on the water content and glass transition of starch materials. Polymer, 38(21), 5401-5406.

Lourdin, D., Putaux, J.-L., Potocki-Véronèse, G., Chevigny, C., Rolland-Sabaté, A., \& Buléon, A. (2015). Crystalline structure in starch. In Starch (pp. 61-90): Springer

Marie Arockianathan, P., Sekar, S., Kumaran, B., \& Sastry, T. P. (2012). Preparation, characterization and evaluation of biocomposite films containing chitosan and sago starch impregnated with silver nanoparticles. International journal of biological macromolecules, 50(4), 939-946.

Martins, A. M., Kretlow, J. D., Costa-Pinto, A. R., Malafaya, P. B., Fernandes, E. M., Neves, N. M., . . Reis, R. L. (2012). Gradual pore formation in natural origin scaffolds throughout subcutaneous implantation. Journal of Biomedical Materials Research Part A, 100A(3), 599-612. 
(C) <2017>. This manuscript version is made available under the CC-BY-NC-ND 4.0 license http://creativecommons.org/licenses/by-nc-nd/4.0/

Nair, L. S., \& Laurencin, C. T. (2007). Biodegradable polymers as biomaterials. Progress in Polymer Science, 32(8-9), 762-798.

Olalla, A. S., Sessini, V., Torres, E. G., \& Peponi, L. (2016), 9 - Smart Nanocellulose Composites With Shape-Memory Behavior. In D. Puglia, E. Fortunati, \& J. M. Kenny (Eds.), Multifunctional Polymeric Nanocomposites Based on Cellulosic Reinforcements (pp. 277-312), William Andrew Publishing

Peponi, L., Arrieta, M. P., Mujica-Garcia, A., \& López, D. (2016), 6 - Smart Polymers. In C. F. Jasso-Gastinel,.\& J. M. Kenny (Eds.), Modification of Polymer Properties (pp. 131-154), William Andrew Publishing

Peponi, L., Navarro-Baena, I., \& Kenny, J. M. (2014), 7 - Shape memory polymers: Properties, synthesis and applications. In M. R. Aguilar De Armas, \& J. S. Román (Eds.), Smart Polymers and their Applications (pp. 204-236), Woodhead Publishing

Peponi, L., Puglia, D., Torre, L., Valentini, L., \& Kenny, J. M. (2014). Processing of nanostructured polymers and advanced polymeric based nanocomposites. Materials Science and Engineering R: Reports, 85(1), 1-46.

Raquez, J.-M., Nabar, Y., Srinivasan, M., Shin, B.-Y., Narayan, R., \& Dubois, P. (2008). Maleated thermoplastic starch by reactive extrusion. Carbohydrate Polymers, 74(2), 159-169.

Schmitt, H., Creton, N., Prashantha, K., Soulestin, J., Lacrampe, M. F., \& Krawczak, P. (2015). Melt-blended halloysite nanotubes/wheat starch nanocomposites as drug delivery system. Polymer Engineering \& Science, 55(3), 573-580.

Sessini, V., Arrieta, M. P., Kenny, J. M., \& Peponi, L. (2016). Processing of edible films based on nanoreinforced gelatinized starch. Polymer Degradation and Stability, 132, 157-168. 
(C) <2017>. This manuscript version is made available under the CC-BY-NC-ND 4.0 license http://creativecommons.org/licenses/by-nc-nd/4.0/

Sessini, V., Raquez, J.-M., Lo Re, G., Mincheva, R., Kenny, J. M., Dubois, P., \& Peponi, L. (2016). Multiresponsive Shape Memory Blends and Nanocomposites Based on Starch. ACS applied materials \& interfaces, 8(30), 19197-19201.

Véchambre, C., Chaunier, L., \& Lourdin, D. (2010). Novel shape-memory materials based on potato starch. Macromolecular Materials and Engineering, 295(2), $115-122$.

Viguié, J., Molina-Boisseau, S., \& Dufresne, A. (2007). Processing and characterization of waxy maize starch films plasticized by sorbitol and reinforced with starch nanocrystals. Macromolecular bioscience, 7(11), 1206-1216.

Vogler, E. A. (1998). Structure and reactivity of water at biomaterial surfaces. Advances in colloid and interface science, 74(1), 69-117.

Vogt, B. D., Soles, C. L., Lee, H.-J., Lin, E. K., \& Wu, W.-1. (2005). Moisture absorption into ultrathin hydrophilic polymer films on different substrate surfaces. Polymer, 46(5), 1635-1642.

Wang, H., Feng, Y., An, B., Zhang, W., Sun, M., Fang, Z., Khan, M. (2012). Fabrication of PU/PEGMA crosslinked hybrid scaffolds by in situ UV photopolymerization favoring human endothelial cells growth for vascular tissue engineering. Journal of Materials Science: Materials in Medicine, 23(6), 14991510.

Ward Small, I., Singhal, P., Wilson, T. S., \& Maitland, D. J. (2010). Biomedical applications of thermally activated shape memory polymers. Journal of materials chemistry, 20(17), 3356-3366.

Yahia, L. (2015). Shape memory polymers for biomedical applications: Elsevier. 
(C) <2017>. This manuscript version is made available under the CC-BY-NC-ND 4.0 license http://creativecommons.org/licenses/by-nc-nd/4.0/

Yin, Y., Ji, X., Dong, H., Ying, Y., \& Zheng, H. (2008). Study of the swelling dynamics with overshooting effect of hydrogels based on sodium alginate-g-acrylic acid. Carbohydrate Polymers, 71(4), 682-689.

Yuan, W., Feng, Y., Wang, H., Yang, D., An, B., Zhang, W., . . . Guo, J. (2013). Hemocompatible surface of electrospun nanofibrous scaffolds by ATRP modification. Materials Science and Engineering: C, 33(7), 3644-3651.

Zhang, H., Wang, H., Zhong, W., \& Du, Q. (2009). A novel type of shape memory polymer blend and the shape memory mechanism. Polymer, 50(6), 1596-1601.

Zhu, B., Ma, D., Wang, J., Zhang, J., \& Zhang, S. (2016). Multi-responsive hydrogel based on lotus root starch. International journal of biological macromolecules, 89, 599-604. 